\title{
GAMIFICATION AND INTERDISCIPLINARY SCIENTIFIC RESEARCH: SCIENTIFIC TEXT MINING
}

\author{
Olga Kononova ${ }^{1}$, Dmitry Prokudin ${ }^{1,2}$, and Angelina Timofeeva ${ }^{1}$ \\ ${ }^{1}$ ITMO University 197101, St. Petersburg, Russia \\ ${ }^{2}$ St. Petersburg State University 199034, St. Petersburg, Russia
}

\begin{abstract}
This study investigates the issues of forming the terminological base of interdisciplinary areas of scientific research to discover new knowledge, to make the prediction, such as to identify the public discourse effects on the dynamics of scientific interests. The goals of this paper are to highlight gamification as interdisciplinary area and to represent the complex approach to contextual knowledge research with scientific text mining on the example of "The gamification in the main spheres of digital society" topic. In the work, we use the capabilities of contextual search and extraction of metadata from texts, describing the use of gamification in various fields of activity, followed by quantitative and qualitative processing of the textual arrays obtained. The knowledge gained was used to expand the capabilities of the synthetic method in the part of the text mining analysis as well as the construction and interpretation technique of subject-specific trends. The conclusion of the research consists in the establishment of the sustainable dependence amongst scientific and public discourse: socio-political initiatives form the modern public life which term-concepts identify not only applying technologies in the life of society as such but the scientific discourse directions.
\end{abstract}

\section{KEYWORDS}

Contextual Knowledge, Contextual Search, Digital Society, Interdisciplinary Scientific Research, Synthetic Technique, Scientific Text Mining, Subject-Specific Trends, Terminological Landscape

\section{INTRODUCTION}

In modern scientific studies, the task of analyzing promising interdisciplinary scientific areas is being actualized, which allows us to predict the relevance of research results in these areas (knowledge) in various fields of social life. There is a lag in the development of scientometric and scientific disciplines from the growth rate of the terminological and categorical base of interdisciplinary scientific fields, which is uncontrollably formed by scientific schools, groups, and individual researchers. The ambiguity of terminology and unstructured information, even with free access, makes it impossible to quickly monitor emerging trends and relationships.

One of the significant trends in modern scientific research is the identification (explication) of contextual knowledge by applying methods, approaches, technologies and tools of Digital Humanities as well as the text mining analysis. Contextual knowledge is usually understood as the ability to "read" the context correctly, to extract and interpret professionally significant information regardless of the origin source. The extraction of relevant information is performed through a contextual search. Contextual search is a method of sequentially searching for fragments of text entries relevant to a user's query and the desired context. In this case, the context is a part of the text, the verbal environment of the selected text element (term-concept) for analysis. The context concept used in this study is interpreted by us as an independent conceptual unit of the categorical apparatus, which can be used as the basis for the classification of scientific texts, visualization of hierarchical and associative relations between terms.

Reinterpretation the role of interdisciplinary disciplines and the applicability of traditional scientific methods in interdisciplinary research is widely covered in scientific publications. Interdisciplinary areas (in fact contexts) are believed to be identified through a thematic search and described quantitatively and qualitatively through various kinds of measurements and procedures. Thus, for instance, K. Okamura, focusing on clusters of highly cited papers widely known as research fronts (RFs), has suggested that 
interdisciplinarity is statistically significantly and positively associated with research impact by focusing on highly cited paper clusters [Okamura K., 2019]. C. Carusi and G. Bianchi have applied the quantifying of journals' interdisciplinarity by exploiting relation between scholars and journals where such scholars do publish [Carusi C., Bianchi G., 2020]. J. Raimbault has offered a measurement methodology that combines the analysis of citation networks and semantic analysis, studying the qualitative laws of relations between endogenous disciplines [Raimbault J., 2019]. The scientists G. Abramo, C. A. D’Angelo, and L. Zhang have used two bibliometric approaches to the measurement of interdisciplinary research at the same time: the analysis of disciplinary diversity in the reference list of publications; the disciplinary diversity of authors of publications [Abramo G., et al., 2018]. C. Piciocchi and L. Martinelli have conducted research on the development of categorical-conceptual apparatuses of various scientific areas, where Digital Humanities methods and approaches are used [Piciocchi C. and Martinelli L., 2016]. The paper on the cultural initiatives and the mapping process of governance and participation dynamics involve an abductive reasoning as a pragmatic approach to advancing the social sciences through a process of "systematic combining" both the analytical framework and the case studies in order to expand the theoretical and empirical understanding of results [Biondia L., et al., 2020]. The methodology of research groups [Pejic-Bacha M., et al., 2020; Jimenez-Marquez, et al., 2019] consists of data extraction, analytical approach (descriptive analysis and text mining), and machine-learning analysis. G. Paré, M. C. Trudel, M. Jaana, S. Kitsiou focus the researchers on the preparation as well as analysis of reviews, and develop their own typology of reviews, encouraging authors to use this typology to position their contribution [Paré G., Trudel M. C., Jaana M., Kitsiou S., 2015]. Gamification studies constitute a significant part of such studies. For instance, Finnish researchers practice intellectual search and analysis of scientific texts in their study, preferring manual data processing [Hamari J., Koivisto J., et al., 2014, 2018, 2019]. The search strategy of Indonesian authors described in their paper "The Approach to the Meta-description of the Interdisciplinary Research Terminological Landscape" consists of "sorting digital libraries, determining keywords, using existing tools in digital libraries to facilitate the search, and taking primary studies obtained for processing" [Purwandari B., et al., 2018].

We propose to use the Synthetic technique in this kind of research, which involves the use of ICT at all stages of the research: from searching and collecting information to its quantitative and qualitative processing. The scientific text mining is based on the technologies of contextual search, explication and mapping of contextual knowledge (contexts). We show the effectiveness of this method to achieve the main goal of the study.

\section{RESEARCH METHODOLOGY}

The general approach to conducting research is to apply the synthetic method in interdisciplinary research to analyze contexts, build and interpret subject-specific trends. The Synthetic technique used is aimed at extracting and processing contextual knowledge from unstructured or semi-structured information resources. Moreover, it allows, through explication and mapping, forming collections of fragments (thematic contexts) that are thematically relevant to the interdisciplinary direction. In the frames of the research, the theoretical and practical results of applying science-research methods for extracting, processing and analyzing contextual knowledge have been analyzed [Kononova O., Prokudin D., 2018]. Thus, the research agenda consists in identifying semantic groups and contexts, revealing patterns and building trends that reflect the development dynamics of topics in the scientific and public discourse. The proposed approach was applied to various interdisciplinary scientific areas for identification and analysis of contextual knowledge in practice (Figure 1). It takes no account of the programs and environment used, the language, and the presentation format of information resources. To demonstrate the general approach, ScienceDirect, the full-text and abstract databases of scientific publications, have been selected as text source. The heterogeneity of the source material led to the choice of information platforms and the environment for the explication of contextual knowledge. Selecting tools, the authors have adhered to the principle of source accessibility to a wide circle of researchers.

\begin{tabular}{|c|c|c|}
\hline 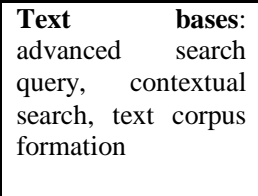 & $\begin{array}{l}\text { Analytic platform: a multilayer thematic query with a } \\
\text { variation of the layers used to highlight aspects of the } \\
\text { subject being explicated; cascade search (the results of } \\
\text { one query are automatically included in the search } \\
\text { image of another query) to identify new elements of } \\
\text { contextual knowledge }\end{array}$ & $\begin{array}{l}\text { Text bases: full-text search; } \\
\text { explication of terminological } \\
\text { landscape; } \\
\text { subject-specific trends; the } \\
\text { formation of context collections: } \\
\text { subject-specific trends }\end{array}$ \\
\hline
\end{tabular}

Figure 1. Phases of identifying and analyzing contextual knowledge in practice 
The first phase of the approach involves the formation of search queries, the terminological core and collections of text materials (thematic collections) relevant to the interdisciplinary direction of scientific research. Thematic collections are formed by performing a sequential iteration of search queries. The second and the third phases of the approach reflect the sequence of steps from the allocation and explication of primary contexts to the construction of subject-thematic trends as a result of repeated thematic queries in previously explicated arrays of text materials.

In parallel with the main process, the identification and formation of a qualitatively new type of contextual knowledge (namely thematic collections of full-text queries) take place. Collections can simultaneously be used both as ready-made thematic knowledge (context), expanding the composition of the information resources of the electronic library, and as a user tool for creating and developing similar collections. In conducting the study and presentation of the results of "The gamification in the main spheres of digital society" pilot study, the full range of the above-mentioned information sources and Voyant-Tools research information environment was used.

\section{GAMIFICATION PILOT STUDY}

To assess the dynamics of research interest in gamification technology, the authors searched and selected scientific publications from the information resources ScienceDirect, Google Scholar (for English), and CyberLeninka, Google Scholar, eLibrary (for Russian sources). The scientific papers corpus obtained were found by the "gamification" search query, and then selected by the expert method according to the attribute "relevance of the subject area of research."

The dynamics study of the terminological landscape development has allowed us to identify trends and connections which are inherent in the contextual knowledge in the interdisciplinary scientific area considered. To track the use of term-concepts close to the term-concept 'gamification' and to construct subject-specific trends, the identification task has required the contextual search of relevant publications in each year separately. The search has been carried out based on the materials published from 2010 to 2019. On the whole, our results have confirmed the conclusions of the previous research that scientific articles on gamification have appeared in the scientific discourse since 2010 [Hamari, et al., 2014; Vanolo A., 2018; Harviainen J. T., Hassan L., 2019; Koivisto, J, Hamari, J., 2019]. The search results for the period previous to 2013 are characterized by single publications in both Russian and World scientific spaces and disaffect the overall view. The number of papers for the period from 2010 to 2012 is insignificant, therefore, the data were not included in the general statistics. The Media search results (via Integrum) from 2013 to 2019 have also demonstrated an annual increase of "The gamification in the main spheres of digital society" topic interest.

The analysis of the data allowed us to make the following conclusions: the number of scientific publications on gamification in the world has been increasing annually since 2010; the dynamics of growth in the number of Russian scientific publications on this topic shows a two-year delay. However, in general, the dynamics correspond to global scientific trends. Based on the application of Phase 3 (Fig. 1), the evolution of the terminology base being formed was predicted. Methods implement text mining analysis on the unstructured or semi-structured data processing and handling to construct subject-specific trends "by identifying relevant words and relationships in order to categorize or draw conclusions" [Pejic-Bacha, M., et al., 2020].

The text mining analysis of English scientific gamification discourse was executed, using Voyant-Tools software (https://voyant-tools.org/). The first pre-processing step was to collect the text array extracted from the full-text database of scientific information Science Direct, 2013-2019, (Fig. 1, Phase 1). The second step was to search, assess, exclude, and explicate the papers relevant to "The gamification in the main spheres of digital society" topic followed by analytic processing to extract relative term-concepts (Fig. 1, Phase 2). There were 275 text sets obtained. To analyze the text sets, a search of collocations with Voyant-Tools has been applied on the base of 'gamification' term-concept with the text context size limited by 11 words at the left and at the right from the key term. The limitation selected allows taking into account and considering as a solid context at least neighboring sentences into texts. As a result of the collocation analyses, semantic groups and relative term-concepts have been obtained. Semantic groups are Economy, Education / Science, Technology, Game Mechanisms, City, and others. The most significant relative term-concepts identified are indicated in descending order of the absolute frequency of collocation occurrences for all text set.

In addition, term-concepts: 'health', 'business', 'engineering', 'participation', 'industry 4.0', 'computing', 'energy', 'transport' have been extracted. These terms were found only in the last two- or three-years papers' sets. However, the appearance of that key words' cluster let us draw a conclusion gradual gamification 
invasion in different branches of social and business human activity. The analysis has identified the main subject areas and spheres of application of gamification as rule on the base of digital technologies. This fact could be unambiguously interpreted as interdisciplinarity. The list of subject areas is stable throughout the studied time interval. The leaders in the frequency of publications are Education, Economics, Organization and Management, Sociology. Depending on the year, the rest occupy different positions in the frequency list. With regard to the contexts of using gamification, the analysis has revealed four directions, in which the growth of not only scientific, but also media discourse, both in the world and in Russia, is especially noticeable. They are urban planning, e-government, e-participation, and e-learning. The construction of subject-specific trends demonstrates the methods suggested on the base of three term-concepts - 'motivation', 'engagement', and 'communication' included in the "Game mechanisms" semantic group in corresponding with Phase 2 (Fig. 1). To compare the common and particular dynamics, the graph of research interest in the gamification topic (the gamification graph) has been added (Figure 2).

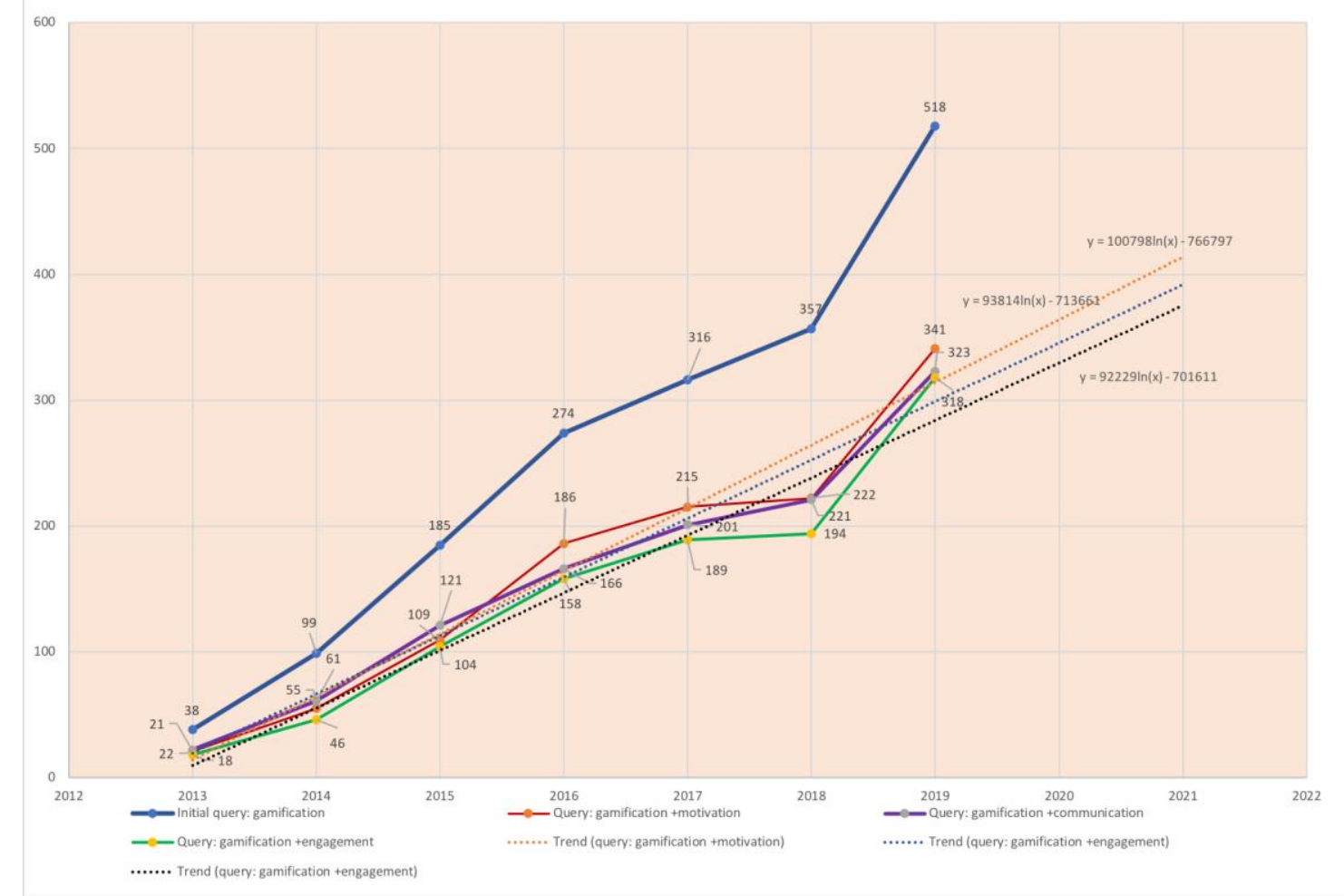

Figure 2. Trends on three relative term-concepts in comparison with the dynamics of 'gamification' as such

Trends on the three identified relative term-concepts ('motivation', 'engagement', 'communication') related to the "Game mechanisms" semantic group have been proving that the study of the mechanics of gamification will continue to be of scientific interest. Moreover, the "gamification as the motivational mechanisms" topic will not lose its significance, the interest in the "gamification as engagement mechanisms" as well as "gamification as communicational mechanisms" topics are expected to continue increasing. Testing the thesaurus of the gamification interdisciplinary area on the updated data of 2019 and data of 2020 will confirm or refute the previously obtained prediction and, consequently, the stability of the results of the proposed approach.

\section{CONCLUSIONS}

To sum up, the study demonstrates the following results: the use of the Synthetic technique allowed us to identify the interdisciplinarity of the direction of scientific research "gamification"; the correlation amongst the dynamics of research interest in topics related to gamification in Russian and World discourse has been 
found; reference-term concepts of a terminological base of "The gamification in the main spheres of digital society" interdisciplinary research area has been identified; Russian scientific discourse depends on the official state environment - the subject of scientific publications reflects the emergence of various governance initiatives; the main contexts have been identified; trends reflected the dynamics of the development of the interdisciplinary area have been constructed. Further research involves the construction of interdisciplinary thesaurus as ontology with semantic characteristics that define the relationship (synonymy, hierarchy, association) among term-concepts, as well as, attributes of term-concepts.

\section{ACKNOWLEDGEMENT}

The reported study is funded by RFBR according to the research project "The integrated approach elaboration to the analysis of the terminological base of the developing interdisciplinary research in distributed network environment” № 18-011-00923, 2018-2020.

\section{REFERENCES}

Abramo, G., D'Angelo, C.A., Zhang, L., 2018. A comparison of two approaches for measuring interdisciplinary research output: The disciplinary diversity of authors vs the disciplinary diversity of the reference list. In Journal of Informetrics, Vol. 12, No. 4, pp. 1182-1193. DOI: 10.1016/j.joi.2018.09.001

Biondia, L., Demartinia, P., Marchegiania, L., Marchioria, M., Piberb, M., 2020. Understanding orchestrated participatory cultural initiatives: Mapping the dynamics of governance and participation. In Cities, Vol. 96, 102459. DOI: $10.1016 /$ j.cities.2019.102459

Carusi, C., Bianchi, G., 2020. A look at interdisciplinarity using bipartite scholar/journal networks. In Scientometrics, No. 122, pp. 867-894. DOI:10.1007/s11192-019-03309-3

Hamari, J., Hassan, L., Dias, A. 2018. Gamification, quantied-self or social net- working? Matching users' goals with motivational technology. In User Modeling and User-Adapted Interaction, Vol. 28, No. 1, pp. 35-74. DOI:10.1007/s11257-018-9200-2

Hamari, J., Koivisto, J., Sarsa, H., 2014. Does Gamification Work? - A Literature Review of Empirical Studies on Gamification. Proceedings of the 2014 47th Hawaii International Conference on System Sciences (HICSS '14). IEEE Computer Society, Washington, DC, USA, pp. 3025-3034. DOI: 10.1109/HICSS.2014.377

Harviainen, J. T., Hassan, L., 2019. Governmental Service Gamification: Central Principles. In International Journal of Innovation in the Digital Economy, Vol. 10, No. 3, pp. 1-12. DOI: 10.4018/IJIDE.2019070101

Hassan, L., Hamari, J., 2019. Gamification of E-Participation: A Literature Review. Proceedings of 52nd Hawaii International Conference on System Sciences (HICSS'52). At Maui HI, USA, pp. 3077-3086.

Jimenez-Marquez, J. L., Gonzalez-Carrasco, I., Lopez-Cuadrado, J. L., Ruiz-Mezcua, B., 2019. Towards a big data framework for analyzing social media contente. In International Journal of Information Management, Vol. 44, pp. 1-12. DOI: 10.1016/j.ijinfomgt.2018.09.003.

Koivisto, J, Hamari, J., 2019. The rise of motivational information systems: A review of gamification research. In International Journal of Information Management, Vol. 45, pp. 191-210. DOI: 10.1016/j.jinfomgt.2018.10.013

Kononova, O., Prokudin, D., 2018. Synthetic Method in Interdisciplinary Terminological Landscape Research of Digital Economy. In SHS Web Conf., Vol. 507, 01082. DOI: 10.1051/shsconf/20185001082

Okamura, K., 2019. Interdisciplinarity revisited: evidence for research impact and dynamism. In Palgrave Communication, Vol. 5, 141. DOI: 10.1057/s41599-019-0352-4

Paré, G., Trudel, M. C., Jaana, M., Kitsiou, S., 2015. Synthesizing information systems knowledge: A typology of literature reviews. In Information \& Management, Vol. 52, No. 2, pp. 183-199. DOI: 10.1016/j.im.2014.08.008

Pejic-Bacha, M., Bertoncelb, T., Meškob, M., Krstićc, Ž, 2020. Text mining of industry 4 job advertisements in International Journal of Information Management, Vol. 50, pp. 416-431. DOI: 10.1016/j.ijinfomgt.2019.07.014

Piciocchi, C, Martinelli, L., 2016. The change of definitions in a multidisciplinary landscape: the case of human embryo and preembryo identification. In Croatian Medical Journal, Vol. 57, No. 5, pp. 510-515. DOI: $10.3325 / \mathrm{cmj} .2016 .57 .510$

Purwandari, B., Sutoyo, M.A.H., Mishbah, M., Dzulfikar, M.F., 2019. Gamification in e-Government: A Systematic Literature Review. Fourth International Conference on Informatics and Computing (ICIC). Semarang, Indonesia, pp. 1-5. DOI: 10.1109/ICIC47613.2019.8985769

Raimbault, J., 2019. Exploration of an interdisciplinary scientific landscape. In Scientometrics, Vol. 119, No. 2, pp. 617-641. DOI: 10.1007/s11192-019-03090-3

Vanolo, A., 2018. Cities and the politics of Gamification. In Cities, Vol. 74, pp. 20-326. DOI: $10.1016 /$ j.cities.2017.12.021 